\title{
PENGARUH KOMUNIKASI DAN MOTIVASI BERPRESTASI TERHADAP KEPUASAN PELANGGAN di PPs UNJ
}

\author{
Desi Rahmawati*
}

\begin{abstract}
The objective of this causal research is to obtain information concerning the effect of communication and achievement motivation on PPs UNJ student satisfaction. The research was conducted by using a survey method with path analysis in testing hypothesis. In this research, PPs UNJ students of the school year 2009/2010 has been choosen as a unit analysis and 211 samples of student were selected in random. The results of the research are as follows: (1) there is a direct positive effect of communication on achievement motivation indicated by the value of the path coefficient $=0.404$; (2) there is a direct positive effect of communication on PPS UNJ student satisfaction indicated by the value of the path coefficient $=0,223$; (3) there is a direct positive effect of achievement motivation on PPs UNJ student satisfaction indicated by the value of the path coefficient $=0,304$. Therefore, student satisfaction can be improved by optimizing the communication made by the director and staff, lecturers and administrative staff to students using a variety of appropriate media to get positive feedback from students. Furthermore, by constantly increasing the motivation of the students themselves.
\end{abstract}

Keywords: Communication, Achievement Motivation, Satisfaction.

\section{PENDAHULUAN}

Perguruan tinggi merupakan satuan pendidikan penyelenggara pendidikan tinggi yang memiliki misi untuk menyelenggarakan Tridharma Perguruan Tinggi, yaitu : Pendidikan, Penelitian dan Pengabdian Masyarakat. Bertolak pada kegiatan pendidikan di perguruan tinggi, salah satu elemen terbesar yang merupakan pelanggan eksternal utama adalah mahasiswa. Maka dari itu, untuk meningkatkan animo masyarakat untuk melanjutkan ke perguruan tinggi tertentu maka sudah sepantasnya perguruan tinggi berlomba-lomba memperbaiki dan mengoptimalkan seluruh perangkat yang dibutuhkan baik secara fisik maupun suasana akademik. Kepuasan terjadi bila anggapan kinerja atau perceived performance jasa sesuai dengan harapan seorang pelanggan (mahasiswa). Terdapat lima dimensi kualitas pelayanan yang dapat menjadikan kepuasan pelanggan, yaitu: Tangible (bukti fisik), reliability (keandalan), responsiveness (ketanggapan), assurance (jaminan kepastian), dan empathy. (berndt and Brink:2004:60). Kepuasan akan terwujud di dalam suasana akademik jika di dalamnya terjadi komunikasi yang baik antara pemberi layanan dan yang dilayani. Wujud dari komunikasi yang berjalan efektif antara pemberi layanan dan yang dilayani tercermin pada adanya saling percaya dan meminimalisir penggunaan atribut-atribut formal, dengan adanya penggunaan berbagai media yang pas untuk berkomunikasi yang juga disesuaikan dengan situasi dan kondisi, baik secara langsung melalui komunikasi tatap muka ataupun secara tidak langsung melalui komunikasi tertulis. Menjadi pendengar aktif bagi pemberi layanan dapat mendorong terjadinya umpan balik yang lebih terbuka dari orang yang dilayani dan yang terakhir yaitu penggunaan bahasa yang mudah difahami. Berdasarkan hasil studi penjajagan yang dilakukan peneliti terhadap mahasiswa dan staf administrasi PPs UNJ didapat informasi tentang beberapa aspek

\footnotetext{
* Dosen Jurusan Manajemen Pendidikan FIP UNJ
} 
yang terkait dengan kepuasan mahasiswa, diantaranya telatnya pemberian nilai oleh dosen pemberi materi kuliah, penggunaan IT dalam penyampaian informasi akademik terutama akses untuk nilai hasil studi masih dirasakan kurang. Selain itu belum ketatnya sistem absensi perkuliahan baik untuk mahasiswa ataupun dosen. Berdasarkan hasil pemaparan di atas, peneliti mencoba melakukan pengkajian tentang pengaruh langsung komunikasi terhadap motivasi berprestasi, pengaruh langsung komunikasi terhadap kepuasan, dan pengaruh langsung motivasi berprestasi terhadap kepuasan.

\section{Kepuasan.}

Mahasiswa di dalam perguruan tinggi dianggap sebagai pelanggan utama. Pelanggan diartikan sebagai "semua orang yang menuntut kita untuk memenuhi suatu standar kualitas tertentu, dan karena itu akan memberikan pengaruh pada performansi (performance) kita" (Gaspersz:2008:33). Dalam pengertian ini pelanggan merupakan orang yang teramat penting yang harus dipuaskan. Sallis (1997:70) mengkategorikan pelanggan menjadi dua kategori, yaitu: pelanggan internal dan eksternal. Pelajar/mahasiswa dianggap sebagai pelanggan eksternal utama, orang tua sebagai pelanggan eksternal kedua dan pemerintah, masyarakat/dunia usaha dan industri dianggap sebagai pelanggan eksternal ketiga. Sedangkan guru/dosen beserta staf diposisikan sebagai pelanggan internal. Perlu diketahui bahwa yang menjadi fokus dari kualitas adalah kepuasan pelanggan. Maka dari itu perlu difahami komponenkomponen yang berkaitan dengan kepuasa pelanggan. Hill and Alexander (2006:2) mendefinisikan "Customer satisfaction is a measure of how your organization's total product performs is relation to a set of customer requirements." (Kepuasan pelanggan adalah ukuran dari bagaimana total produk organisasi berhubungan dengan kebutuhan pelanggan).

Zeithaml and Bitner yang dikutip Huseyin Gungor (2007:14) mengidentifikasi terdapat tiga dimensi utama kepuasan pelanggan, yaitu : harga, kualitas produk, dan kualitas layanan. Kualitas layanan juga memiliki tiga sub dimensi, yaitu : kualitas interaksi, kualitas hasil, dan kualitas lingkungan fisik. Sub dimensi tersebut dianalisis kembali menjadi lima dimensi yang dikenal dengan SERVQUAL : responsiveness, assurance, empathy, tangibles, and reliability. Yang selanjutnya dapat dilihat pada tabel berikut :

Tabel 1

Dimension of service quality (SERVQUAL)

\begin{tabular}{|l|l|}
\hline Responsiveness & Willingness to help customers and provide prompt service \\
\hline Assurance & $\begin{array}{l}\text { Employee's knowledge and courtesy and their ability to inspire trust } \\
\text { and confidence }\end{array}$ \\
\hline Empathy & Caring, individualized attention given to customers \\
\hline Tangibles & $\begin{array}{l}\text { Appearance of physical facilities, equipment, personnel and written } \\
\text { materials }\end{array}$ \\
\hline Reliability & Ability to perform the promised service dependably and accurately \\
\hline
\end{tabular}


Banyak variabel yang mempengaruhi kepuasan. Mosley and Megginson (2005:112) Dalam Buku Supervisory Management menggambarkan faktor-faktor yang berpengaruh terhadap kepuasan seperti terlihat pada gambar berikut:
Causal Variables
Intervening Variables
End-Result

Variables

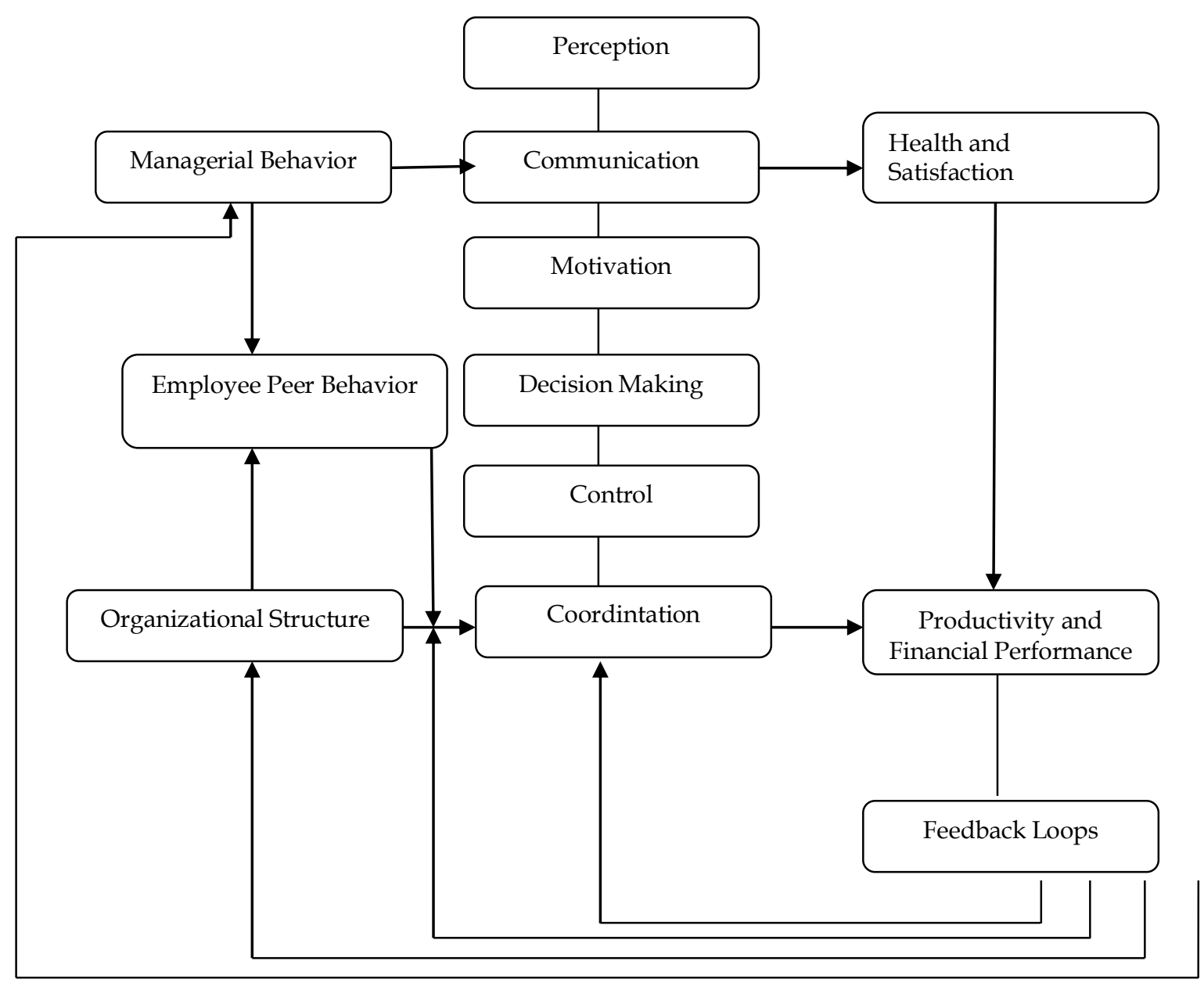

Gambar 1. System Internal Model Likert

Gambar di atas menunjukkan model sistem internal (system internal model) likert. Model ini terdiri dari tiga kategori variabel, yaitu : causal, intervening and result.

Causal variables : these variables determine the course of developments within an organization and the results achieved by the organization. they include only those independent variables that can be altered or changed by the organization and its management. Causal variables include the structure of the organization, and management's policies;decision, business, and leadership strategies;skills; and behavior. (variabel penyebab : variabel-variabel ini menentukan arah perkembangan suatu organisasi dan hasil yang dicapai oleh organisasi. Variabel ini mencakup variabel-variabel independen yang dapat diubah oleh organisasi dan manajemen. variabel penyebab mencakup struktur organisasi, dan kebijakan manajemen; keputusan, bisnis, dan strategi kepemimpinan, keterampilan, dan perilaku) Intervening variables : these reflect the internal state and heal th of the organization. they include the loyalities, attitudes, motivations, performance goals, and perceptions of organization members and their capacities for the effective interaction, communication, and decision making. (Variabel 
perantara : variabel ini merefleksikan kondisi internal dan kesehatan organisasi. termasuk loyalitas, sikap, motivasi, tujuan kinerja, persepsi anggota organisasi dan kemampuan mereka untuk interaksi yang efektif, komunikasi, dan pengambilan keputusan)

End-result variables. These are dependent variables that reflect the achievements of the organization, such as productivity, costs, scrap loss, and earnings. (variabel hasil : ini adalah variabel terikat yang mencerminkan prestasi organisasi, seperti produktivitas, biaya, kerugian, dan pendapatan.

Dari pemaparan di atas, dapat disintesakan bahwa kepuasan pelanggan merupakan perasaan puas atau tidak puas pelanggan atas pelayanan yang diberikan dengan indikator: pemenuhan kebutuhan sarana, pemberian layanan tepat waktu, pemberian layanan yang cepat, ramah, kompeten dan pemberian kemudahan.

\section{Komunikasi.}

Menurut kreitner and Kinicki (2007:439) komunikasi diartikan sebagai "Communication is the exchange of information between a sender and a receiver, and the inference (perception) of meaning between the individuals involved" (komunikasi merupakan pertukaran informasi antara pengirim dan penerima, dan mempersepsikan makna antara individu yang terlibat). Pertukaran di sini dimaksudkan proses dua arah yang terdiri dari beberapa unsur yang saling terkait. Unsur-unsur tersebut dapat digambarkan sebagai berikut :

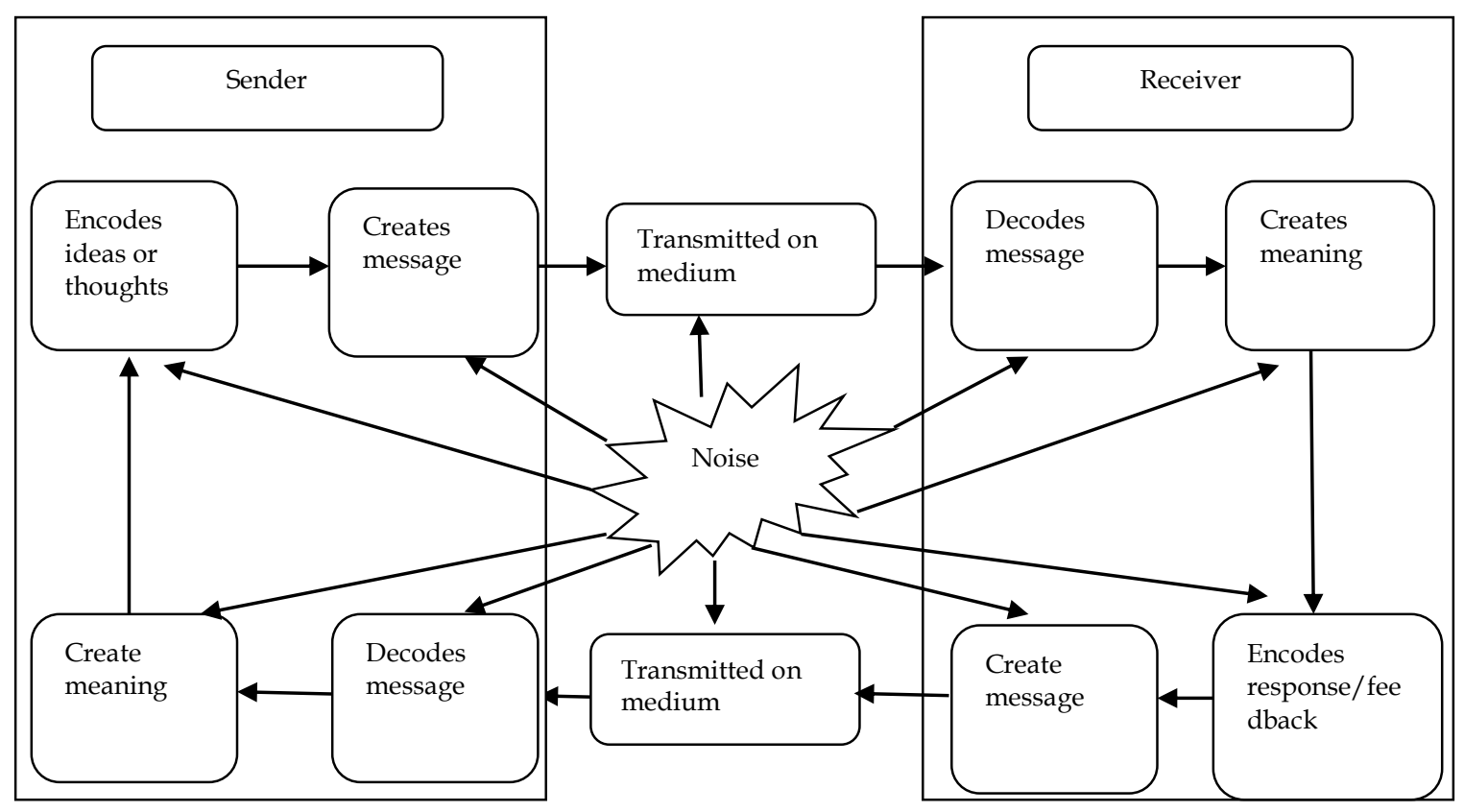

Gambar 2. A perceptual model of communication

Menurut Robbins and Coulter (2007:322) "Communication is the transfer and understanding of meaning" (Komunikasi merupakan penyampaian dan pemahaman suatu maksud). Penyampaian maksud diartikan bahwa jika tidak ada informasi atau

ide yang disampaikan, komunikasi tidak terjadi dan yang penting lagi komunikasi mencakup pemahaman maksud. Agar komunikasi berhasil, maksud harus ditanamkan dan dipahami. Komunikasi menurut George and Jones (2005:437) diartikan pula sebagai 
"communication is the sharing of information between two or more individuals or groups to reach a common understanding" (Komunikasi merupakan pertukaran informasi antara dua atau lebih individu atau kelompok untuk mendapatkan pemahaman bersama). Dari definisi tersebut komunikasi harus melibatkan sedikitnya dua orang individu.

Dalam Buku Supervisory Management, Mosley, Megginson, and Pietri (2005:171) mengemukakan cara meningkatkan komunikasi yang efektif bagi para pemimpin, yaitu dengan cara : Set the proper climate with your employees, Plan your communication, Use repetition to reinforce key ideas, Encourage the use of feedback, and Become a better listener. Hal utama yang perlu diperhatikan oleh para pemimpin dalam meningkatkan komunikasi yang efektif yaitu dengan menciptakan iklim komunikasi yang sesuai dengan anggota. Untuk menciptakan itu dibutuhkan adanya saling percaya antara pemimpin dengan anggota dan meminimalisir penghalang status, seperti : cara berpakaian, formalitas, dan aturan kantor, dan lain-lain. Selanjutnya dengan membuat rencana terlebih dahulu untuk dapat berkomunikasi efektif sesuai dengan situasi dan kondisi dan memilih media yang pas untuk berkomunikasi, apakah melalui tatap muka, telepon, memo/surat, email, atau dengan konferensi elektronik. Selain itu Gibson et al (2006:448449) mengemukakan beberapa teknik yang dapat meningkatkan kemampuan komunikasi para manajer: Following up (tindak lanjut), Regulating information flow (mengatur arus informasi), Utilizing feedback (memanfaatkan umpan balik), Empathy (empati), Repetition (pengulangan), Encouraging mutual trust ( mendorong rasa saling percaya), Effective timing (penggunaan waktu secara efektif), Simplifying language (penggunaan bahasa yang sederhana), and Effective listening (pendengar efektif).

Dari berbagai definisi di atas, maka dapat disintesakan bahwa komunikasi merupakan proses pertukaran informasi antara pengirim dan penerima baik secara langsung maupun tidak langsung untuk mendapatkan pemahaman bersama dengan indikator : Adanya rasa saling percaya, penggunaan media yang tepat, pendengar aktif, adanya umpan balik, dan penggunaan bahasa yang mudah difahami.

\section{Motivasi Berprestasi.}

Mitchell dalam Mullins (2005:471) mendefinisikan motivasi "motivation as the degree to which an individual wants and chooses to engage in certain specified behavior" (Motivasi sebagai tingkat keinginan dan pilihan seseorang untuk melaksanakan perilaku tertentu). Seseorang yang tidak memiliki keinginan tidak akan terdorong untuk melakukan tindakan. Untuk itu seseorang yang memiliki motivasi adalah mereka yang memiliki keinginan sehingga ia berusaha melakukan kegiatan untuk memenuhi keinginannya. Pendapat selanjutnya mengenai motivasi dikemukakan oleh Slocum and Hellriegel (2007:393) yang mengatakan "Motivation represents the forces acting on or within a person that cause the person to behave in a spesific, goal-directed manner." (Motivasi merupakan dorongan untuk bertindak di dalam diri seseorang yang menyebabkan orang itu berperilaku secara spesifik yang diarahkan untuk mencapai tujuan). Dengan adanya motivasi dapat mengarahkan seseorang untuk bertindak secara spesifik sehingga memudahkan dalam pencapaian tujuan.

Selanjutnya definisi mengenai motivasi berprestasi (achievement motivation). McClelland yang dikutip oleh Maehr (2009:185) mendefinisikan motivasi berprestasi "achievement motivation as an individual need or drive to compete and strive to succeed against a standard of excellence in task situations where the outcome was evaluated in term of success 
and failure." (Motivasi berprestasi sebagai kebutuhan individu atau dorongan untuk bersaing dan berusaha untuk berhasil terhadap suatu standar keunggulan dalam situasi tugas di mana hasilnya dievaluasi baik berhasil dan gagal). Pendapat yang diajukan memiliki kesamaan pandangan, diantaranya yaitu adanya dorongan untuk bersaing dan berusaha untuk berhasil. Slocum and Hellriegel (2007:398) mengemukakan tentang karakteristik orang yang memiliki motivasi berprestasi tinggi, yaitu: "they like to set their own goals, avoid selecting extremely difficult goals, and prefer task that provide immediate feedback." (Menetapkan tujuan pribadi mereka, menghindari tujuan yang sulit dicapai, dan melakukan tugas dengan umpan balik langsung). Selanjutnya dalam bukunya Mullin (2005:488), McClelland memaparkan empat karakteristik orang yang memiliki motivasi berprestasi yang tinggi, yaitu: They prefer moderate task difficulty and goals as an achievement incentive, They prefer personal responsibility for performance, They have the need for clear and unambiguous feedback on how well they are performing, and They are more innovative.

Sedangkan menurut Wainer yang dikutip sudjanto (2007:112) orang-orang yang memiliki motivasi berprestasi tinggi ditandai oleh: 1) berusaha untuk melakukan kegiatan yang akan meningkatkan prestasi, 2) berusaha untuk menghindari terjadinya kegagalan, 3) bekerja dengan intensitas yang lebih tinggi, dan 4) memilih tugas yang mempunyai tingkat kesulitan yang sedang. Berdasarkan uraian tersebut dapat disintesakan bahwa motivasi berprestasi adalah dorongan seseorang untuk melakukan kegiatan yang diarahkan untuk mencapai hasil yang terbaik dengan indikator: pemilihan pekerjaan yang dapat dijangkau, bertanggung jawab, berusaha keras mencapai keberhasilan, serta jelas dan realistis dalam menetapkan tujuan.

\section{METODE}

Metode penelitian yang digunakan adalah metode survey. penelitian ini dilakukan pada mahasiswa PPs UNJ angkatan 2009/2010 dengan sampel sebanyak 211 responden. Kegiatan penelitian pada bulan April 2010 sampai dengan bulan Juli 2010.

\section{HASIL DAN PEMBAHASAN}

Berdasarkan hasil pengujian persyaratan analisis data dan pengujian hipotesis diperoleh hasil bahwa hipotesis yang diajukan dalam penelitian ini diterima. hal ini berarti terdapat pengaruh langsung dan tidak langsung positif antara variabel-variabel komunikasi, motivasi berprestasi dan kepuasan mahasiswa. Secara terinci hasil analisis dan pengujian hipotesis tersebut dapat dijelaskan sebagai berikut:

Pertama, komunikasi terbukti mempunyai pengaruh langsung positif terhadap motivasi berprestasi mahasiswa dengan $\rho_{21}=0,404$. Terdapatnya pengaruh langsung positif tersebut terkandung makna bahwa apabila informasi yang ingin disampaikan dapat diterima dan difahami dengan baik maka terjadi komunikasi yang efektif sebagaimana yang dikemukakan oleh Robbins and Coulter (2007:322) yang mengatakan bahwa komunikasi pada dasarnya adalah proses penyampaian dan pemahaman akan suatu hal. Dalam berkomunikasii tidak cukup hanya dengan saling bertukar informasi akan tetapi lebih dari itu, komunikasi baru dapat berjalan efektif jika pesan yang ingin disampaikan difahami oleh kedua belah pihak. Adapun pihak-pihak yang terlibat dalam komunikasi antara lain direktur beserta jajarannya, dosen dan staf administrasi dan mahasiswa. Dengan penekanan yang menjadi komunikator dominan adalah direktur beserta jajarannya, dosen dan staf dan yang menjadi komunikan dominan adalah mahasiswa. Agar pesan yang ingin disampaikan oleh komunikator dapat difahami 
dengan baik oleh komunikan, maka perlu dilakukan secara verbal dan nonverbal sebagaimana yang dikemukakan oleh Gibson et al (2006:427) bahwa komunikasi diartikan sebagai pengiriman informasi dan pemahaman, baik secara verbal maupun nonverbal. Komunikasi akan berjalan efektif jika antara kedua belah pihak memiliki rasa saling percaya. Rasa saling percaya ini dapat dibangun dengan cara meminimalisir kritikan. Selain itu dalam penyampaian informasi juga sebaiknya dilakukan dengan menggunakan media yang tepat. Berbagai media yang dapat digunakan agar pesan yang disampaikan dapat diterima dan difahami dengan baik, diantaranya melalui tatap muka, telepon, email, surat, memo, maupun bulletin. Komunikasi secara tatap muka dan telepon dianggap sebagai media yang efektif untuk menghasilkan informasi yang lengkap karena memungkinkan adanya pesan verbal dan nonverbal dan adanya balikan secara langsung. Telepon meskipun tidak ada kontak fisik, tetapi masih memungkinkan terjadinya informasi nonverbal melalui nada suara. Sedangkan komunikasi melalui media email, surat, memo, maupun buletin tidak memungkinkan terjadinya komunikasi nonverbal dan balikan secara langsung akan tetapi komunikasi ini berguna dalam memberikan pengumuman, kebijakan rutin maupun dalam menyajikan data. Selain itu, komunikasi dapat berjalan efektif jika komunikator dan komunikan mampu menjadi pendengar aktif dalam arti tidak mendominasi pembicaraan dan mendengarkan dengan tujuan bukan untuk menjawab akan tetapi untuk mendapatkan pemahaman, dengan adanya umpan balik memberi kesempatan bagi komunikan untuk merespon dan juga komunikator dapat memastikan bahwa pesan dapat diterima dan di respon sesuai yang dimaksudkan. Selain itu penggunaan bahasa yang mudah difahami oleh kedua belah pihak dapat lebih memudahkan keduanya memahami apa yang dibicarakan. Penggunaan bahasa yang kompleks dapat menjadi penghalang komunikasi efektif karena adanya ketidakfahaman dari salah satu pihak sehingga pesan yang ingin disampaikan tidak difahami secara utuh. Komunikasi yang minim tidak memungkinkan mahasiswa untuk memperoleh informasi yang mereka butuhkan, terutama informasi terkait penyelesaian studi. ini akan menyebabkan rendahnya motivasi berprestasi mahasiswa. Begitupun sebaliknya, informasi yang berlebih sangat memungkinkan berkurangnya keefektikan komunikasi, mahasiswa akan cenderung membuang, mengabaikan, melewatkan bahkan melupakan informasi. Hal ini didukung oleh George and Jones (2005:440) yang mengatakan bahwa komunikasi memainkan peran penting dalam memotivasi anggota yang dalam penelitian ini adalah mahasiswa. Pihak pimpinan dapat melakukan hal-hal seperti: Menjelaskan usaha apa yang harus dilakukan mahasiswa untuk mencapai hasil yang diharapkan. Dalam hal ini maka pimpinan menjelaskan prosedur akademik yang memungkinkan mahasiswa dapat menyelesaikan studi tepat waktu. Selain itu memastikan bahwa mahasiswa belajar dengan sungguh-sungguh, maka pihak pimpinan perlu memastikan perangkatperangkat penunjang pembelajaran dapat terpenuhi untuk menunjang kegiatan akademik mahasiswa. Dan terakhir memberikan keyakinan pada mahasiswa bahwa mereka mampu mencapai prestasi terbaik.

Kedua, pengaruh langsung komunikasi terhadap kepuasan mahasiswa. Terdapat pengaruh langsung positif komunikasi terhadap kepuasan mahasiswa yang ditunjukkan oleh koefisien jalur $\rho_{31}$ sebesar 0,223. Dengan kekuatan seperti itu mengandung makna bahwa penyampaian informasi akademik yang dilakukan oleh direktur beserta jajarannya, dosen dan staf administrasi kepada mahasiswa baik secara langsung maupun tidak langsung untuk mendapatkan pemahaman bersama memberi pengaruh terhadap kepuasan mahasiswa. Sebagaimana yang dikemukakan oleh Gibson (2006:94) bahwa kemampuan dalam berbicara dan mendengarkan yang merupakan 
bagian dari komunikasi dapat mempengaruhi kepuasan. Terkait kemampuan berbicara, maka dalam menyampaikan informasi akademik, direktur beserta jajarannya, dosen dan staf administrasi harus memastikan bahwa informasi yang diberikan diterima dan difahami dengan baik oleh mahasiswa yakni dengan didukung oleh simbol-simbol nonverbal, seperti : gerakan tubuh dan ekspresi wajah yang bersahabat. Dalam penyampaian pesannya pun, perlu didukung oleh intonasi yang jelas. Di samping itu kemampuan mendengarkan amat penting dalam berkomunikasi. Direktur beserta jajarannya, dosen dan staf administrasi diharapkan mampu menjadi pendengar yang empatik yang memiliki keterampilan dalam mendengarkan, sabar dan responsif. Maka dari itu dalam melakukan komunikasi penting untuk melakukan beberapa hal sesuai dengan yang dikemukakan Mosley, Megginson, and Pietri (2005:171) yakni dengan cara : menumbuhkan rasa saling percaya antara kedua belah pihak dan meminimalisir penghalang status seperti jabatan dan peraturan formal, dengan memilih media yang paling pas dalam berkomunikasi apakah melalui tatap muka, telepon, memo/surat, email, atau dengan konferensi elektronik. Selanjutnya dengan melakukan teknik mendengarkan aktif. Mendengarkan aktif merupakan salah satu teknik mendengarkan yang menempatkan direktur beserta jajarannya, dosen dan staf administrasi sebagai penerima dan mendorong terjadinya umpan balik dari mahasiswa. Dengan terjadinya komunikasi yang efektif, maka dapat meningkatkan kepuasan mahasiswa. Kepuasan mahasiswa merupakan perasaan puas mahasiswa atas pelayanan yang diberikan dan terpenuhinya kebutuhan, keinginan, dan harapannya. Terkait dengan pemenuhan kebutuhan, keinginan dan harapannya. Ketika harapan mahasiswa agar memperoleh layanan akademik terpenuhi, maka dapat dikatakan bahwa mahasiswa merasa puas. Layanan akademik dapat berupa pemenuhan kebutuhan sarana, pemberian layanan tepat waktu, pemberian layanan yang cepat, para pemberi layanan kompeten dan ramah, serta memberikan kemudahan pada mahasiswa.

Ketiga, pengaruh langsung motivasi berprestasi terhadap kepuasan mahasiswa. Terdapat pengaruh langsung positif motivasi berprestasi terhadap kepuasan mahasiswa yang ditunjukkan oleh koefisien jalur $\rho_{32}$ sebesar 0,304. Dengan kekuatan pengaruh seperti itu terkandung makna bahwa untuk meningkatkan kepuasan mahasiwa, maka mahasiswa yang bersangkutan harus memiliki motivasi berprestasi yang tinggi baik secara eksternal maupun internal. Sebagai mahasiswa dalam menjalankan kegiatan akademik harus mampu memotivasi dirinya sendiri secara maksimal sehingga akan memiliki dorongan untuk mengoptimalkan kemampuannya. Slocum and Hellriegel (2007:393) mengemukakan bahwa motivasi merupakan dorongan untuk bertindak di dalam diri seseorang yang menyebabkan orang itu berperilaku secara spesifik yang diarahkan untuk mencapai tujuan. Tersirat pada pandangan ini bahwa untuk mencapai tujuan mahasiswa harus memiliki motivasi yang kuat. Selanjutnya motivasi seseorang harus diberi energi, diarahkan dan berkelanjutan sebagaimana diungkapkan oleh Robbins and Coulter yang menyatakan bahwa motivasi mengacu pada proses di mana usaha seseorang diberi energi, diarahkan, dan berkelanjutan menuju tercapainya tujuan. Motivasi berprestasi ditunjukkan dengan dorongan untuk bersaing dan berusaha untuk berhasil terhadap suatu standar keunggulan dalam situasi tugas di mana hasilnya dievaluasi baik berhasil atau gagal (Maehr:2009:185). Mahasiswa dengan motivasi berprestasi tinggi dapat dilihat dari usahanya untuk mencapai keberhasilan sesuai standar yang telah ia buat terlepas ia berhasil atau gagal. Selain itu motivasi berprestasi pada mahasiswa dapat terlihat pula pada kemampuannya mengupayakan yang terbaik, mengupayakan kemajuan, melakukan hal-hal yang lebih baik, lebih cepat, lebih efisien, melakukan sesuatu yang unik atau bersaing secara sehat. Motivasi berprestasi pada 
mahasiswa terbukti memberi pengaruh terhadap kepuasan mahasiswa. Hal ini sesuai dengan teori yang dikemukakan oleh Gibson (2006:94) bahwa motivasi berpengaruh terhadap kepuasan. Slocum dan Hellriegel (2007:398) mengemukakan tentang karakteristik orang yang memiliki motivasi berprestasi tinggi, yaitu : jelas dan realistis dalam menetapkan tujuan, menghindari tujuan yang sulit dicapai, dan cenderung melakukan tugas dengan umpan balik langsung. Motivasi berprestasi bisa datang dari dalam dan dari luar. Faktor yang datang dari dalam seperti tujuan individu, emosi, minat intrinsik, dan kepercayaan diri sedangkan faktor yang datang dari luar adalah lingkungan sosial. Lingkungan sosial bisa orang tua, teman, dan orang-orang yang berinteraksi dengan mahasiswa seperti direktur beserta jajarannya, dosen, dan staf administrasi. Maka dari itu direktur beserta jajarannya, dosen, dan staf administrasi dituntut untuk dapat memberikan rangsangan dan memotivasi mahasiswa sehingga mahasiswa dapat menjalankan kegiatan akademik dengan baik, bertanggung jawab, dapat berusaha mencapai keberhasilan dan lebih focus dalam menetapkan tujuan. Hal yang demikian diperlukan untuk dapat meningkatkan kepuasan mahasiswa

\section{PENUTUP}

Kesimpulan. Terdapat pengaruh langsung positif komunikasi terhadap motivasi berprestasi mahasiswa PPs UNJ. Terdapat pengaruh langsung positif komunikasi terhadap kepuasan mahasiswa PPs UNJ. Terdapat pengaruh langsung positif motivasi berprestasi terhadap kepuasan mahasiswa PPs UNJ.

Saran. Bagi PPs UNJ sebagai penyedia layanan, hendaknya dapat memberikan informasi akademik dengan lebih jelas dan dengan penggunaan berbagai media yang tepat, terutama informasi mengenai pedoman penyelesaian studi bagi mahasiswa, mahasiswa mengharapkan adanya buku pedoman akademik yang dapat dijadikan pedoman dalam menjalankan studi di PPs UNJ. Selain itu, aspek lain yang perlu juga mendapat perhatian terkait dengan kepuasan mahasiswa adalah menyediakan sarana dan prasarana yang lebih nyaman, mengadakan jasa foto kopi di dalam gedung PPs UNJ dengan alasan efisiensi jarak dan waktu dan juga diharapakan PPs UNJ, menyediakan informasi beasiswa yang lebih banyak dan dapat diakses oleh seluruh mahasiswa PPs UNJ. Bagi mahasiswa PPs UNJ, berkaitan dengan peningkatan motivasi berprestasi, maka diharapkan tidak mudah menyerah dalam menyelesaikan tugas-tugas perkuliahan, dapat menyelesaikan tugas yang diberikan oleh dosen secara optimal, tidak menunda-nunda mengerjakan tugas perkuliahan, memanfaatkan waktu senggang dengan membaca buku, dan diusahakan membuat rencana terlebih dahulu sebelum melakukan pekerjaan.

\section{DAFTAR RUJUKAN}

Berndt, Adele and Annekie Brink, Customer Relationship Management and Customer Service. South Africa : Juta and Co Ltd, 2008.

Brown, Mark Graham. Baldrige Award Winning Quality. 17th Edition. New York:Productivity Press, 2008.

Edward Sallis, Total Quality Management In Education, Penterjemah Ahmad Ali Riyadi Fahrurrozi. Jogjakarta: IRCiSoD, 1997. 
Gaspersz, Vincent. Total Quality Management. Jakarta: PT: Gramedia Pustaka Utama, 2008.

George, Jennifer M. and Gareth R. Jones, Understanding and Managing Organizational Behavior, Fourth Edition. New Jersey: Pearson Prentice Hall, 2005.

Gibson, James L. et al, Organizations: Behavior, Structure, Process, Twelfth Edition. New York: Mc Graw Hill, 2006.

Gungor, Huseyin. Emotional Satisfaction of Customer Contacs. Amsterdam : Amsterdam University Press, 2007.

Hill, Nigel and Jim Alexander, Handbook of Customer Satisfaction and Loyalty Measurement. USA : Gower Publishing Company, 2002.

Jr, John W. Slocum, and Don Hellriegel, Fundamentals of Organizational Behavior. Thomson South-Western, 2007.

Kreitner, Robert and Angelo Kinicki, Organizational Behavior, Seventh Edition. New York: McGraw-Hill, 2007.

Maehr, Martin L. Culture, Self And Motivation : Essay in Honor of Martin L.Maehr. USA : Age Publishing, Inc, 2009.

Mosley, Donald C. Leon C. Megginson, and Paul H.Pietri, Supervisory Management: The Art of Inspiring, Empowering, and Developing People. Ohio : Thomson SouthWestern, 2005.

Mullins, Laurie J. Management And Organizational Behavior, Seventh Edition. England: Prentice Hall Financial Times, 2005.

Robbins, Stephen and Mary Coulter, Management, Ninth Edition. New Jersey : Pearson Prentice Hall, 2007. 